\title{
Investigation of mechanical and physicochemical properties of clinically retrieved titanium-niobium orthodontic archwires
}

\author{
Angelina Stoyanova-IVANOVA ${ }^{1}$, SABINA CHERNEVA ${ }^{2 *}$, Vladimir PETRUNOV ${ }^{3}$, \\ VIOLETA PETROVA ${ }^{1}$, IVANA ILIEVSKA ${ }^{1}$, VALDEK MIKLI ${ }^{4}$, ROUMEN IANKOV ${ }^{2}$ \\ ${ }^{1}$ G. Nadjakov Institute of Solid State Physics, Bulgarian Academy of Sciences, Sofia, Bulgaria. \\ ${ }^{2}$ Institute of Mechanics, Bulgarian Academy of Sciences, Sofia, Bulgaria. \\ ${ }^{3}$ Faculty of Dental Medicine, Medical University of Sofia, Sofia, Bulgaria. \\ ${ }^{4}$ Institute of Materials and Environmental Technology, Tallinn University of Technology, Tallinn, Estonia.
}

Purpose: Most of the orthodontic archwires used in the clinical practice nowadays contain nickel (Ni), however, many patients, especially kids, are allergic to Ni. One possible Ni-free alternative is the Titanium-Niobium (Ti-Nb) archwire. Unfortunately, there is not enough information about its mechanical properties in the literature, especially after clinical usage. Therefore, the aim of this work was to investigate and compare the mechanical properties, chemical composition, structure and morphology of as received and used in clinical practice Ti-Nb orthodontic archwires. Materials and methods: We investigated and compared as received and clinically retrieved after 4 and 6 weeks respectively Ti-Nb archwires with dimensions $0.43 \times 0.64 \mathrm{~mm}(0.017 \mathrm{in} . \times 0.025 \mathrm{in}$.). The following methods were used: instrumented indentation testing (nanoindentation), X-ray diffraction, scanning electron microscopy, energy-dispersive X-ray spectroscopy and X-ray photoelectron spectroscopy. Results: The nanoindentation investigations of as received and used Ti-Nb archwires revealed a decreasing in their indentation hardness with increased periods of use in the patient's mouth. Moreover, an increasing of the concentration of $\mathrm{Ti}$ in the content of the TiNb alloy was associated with an increased period of use in the oral cavity. The SEM analysis showed changes in surface morphology with increasing the period of use of the archwires. Conclusions: The results showed that there are slight changes in the mechanical and physicochemical properties of the investigated wires after their use in the patient's mouth. That is why we do not recommend them for recycling.

Key words: Ni-free orthodontic wires, titanium-niobium, mechanical properties, morphology, chemical composition, structure

\section{Introduction}

In modern orthodontic practice, a variety of metallic alloys are used: stainless steel, nickel-titanium, titanium-molybdenum and others. The choice of a suitable archwire is based primarily on its mechanical properties, as it largely determines its effectiveness. The question of the biological tolerance of materials placed in the patient's mouth must not be overlooked. Most of the above-mentioned archwires contain Ni [7]. Janson et al. [17] found that this element can cause an immunological reaction, most commonly contact hypersen- sitivity. The solution to this problem is quite complex due to the significantly high requirements regarding the mechanical properties of the orthodontic archwires. According to Bai et al. [3], the basic advantages of titanium and its alloys (Titanium-Molybdenum alloy (TMA) and Titanium-Niobium (Ti-Nb)) as Ni-free alternatives in dentistry are their good biocompatibility, good corrosion resistance and high strength. The properties of TMA wires are well studied [18], [19], [27], but there is not enough information about the mechanical properties of $\mathrm{Ti}-\mathrm{Nb}$ archwires, especially after clinical use. The Ti-Nb archwires were introduced by the producer as finishing wires with stiffness

* Corresponding author: Sabina Cherneva, Institute of Mechanics, Bulgarian Academy of Sciences, Acad. G. Bontchev St., bl. 4, 1113 Sofia, Bulgaria. Phone: +359 297967 51, e-mail: sabina_cherneva@yahoo.com

Received: October 23rd, 2019

Accepted for publication: December 12th, 2019 
by $20 \%$ lower than TMA [24]. Their advantages are that their stiffness in bending is about one half of that of stainless steel and in torsion it is about one-third, which gives the possibility to clinicians to use them for creative bends without the excessive force levels of steel wires. Moreover the titanium-niobium wires can be used even for third-order corrections, because their springback in bending is by $14 \%$ lower than that of steel and in torsion is slightly higher than that of steel. Dalstra et al. [6] found that the titaniumniobium wires have good weldability, that is why wires of different dimensions can be weld together in order differentiated force systems to be generated. Huang et al. [9] showed that they exhibit extremely high corrosion resistance thanks to the surface layer of $\mathrm{Nb}_{2} \mathrm{O}_{5}$. On the other hand, their basic disadvantage is their high cost.

Although knowing the mechanical properties of orthodontic archwires is very important for their application, this information is usually not provided in the producers' catalogues and specifications. For example, elastic modulus is one of the most important factors for the clinical performance of orthodontic archwires. Hardness is also very important, because it is connected with the wire movement and strength. A lot of techniques (e.g., tensile tests, the three point bending test, etc.) can be used to investigate of the mechanical properties of orthodontic archwires. Most of them require large sections of wire and provide mean values. The advantage of the nanoindentation technique is that it gives local mechanical properties with high resolution and does not require preliminary sample preparations. Most of the related investigations of the mechanical properties of orthodontic archwires by this moment have focused on stainless steel, cobalt-chromium-nickel alloy, beta-titanium alloy and Ni-Ti wires [1], [10], [11], [14], [21]; however, there is insufficient research about the mechanical properties of archwires made from Ti-Nb, Timolium, and others [19], [28]. In our opinion, the inadequate information about the mechanical properties, metal structure and surface characteristics of $\mathrm{Ti}-\mathrm{Nb}$ archwires is the main reason why they are not widely used in the orthodontic practice. Other key questions are whether this archwire changes its chemical structure and mechanical properties after intraoral application and whether it could be used as substitute of TMA wires in similar clinical situations.

There are other studies on as received $\mathrm{Ti}-\mathrm{Nb}$ orthodontic archwires [6], [12], but we did not find enough information about the changes of their mechanical properties after usage in the patient's mouth. That is why the aim of this study was to in- vestigate the mechanical properties, morphology, chemical composition and structure of clinically retrieved Ti-Nb orthodontic archwires in order to evaluate the changes of their properties after clinical usage and understand whether it is possible to be recycled in the future, as reported by other authors for other types of orthodontic arches [2], [5], [15], [20]. Also, based on the acquired knowledge about the mechanical and physicochemical properties of the material, we think that it is possible to increase the indication of clinical use, especially in the cases where the patient is allergic to $\mathrm{Ni}$.

\section{Materials and methods}

\subsection{Materials}

In the present work, we investigated as received archwires, as well as wires used for 4 and 6 weeks in the patient's mouth. All the clinical procedures were carried out in compliance with the guidelines of the Bulgarian Ministry of Health for Good Clinical Practice and The World Medical Association's Declaration of Helsinki. We informed the patients in advance that the retrieved archwires will be tested in vitro and they agreed to this. All tests were performed in laboratory conditions, without direct patient participation. We asked seven consecutive patients who fulfilled the inclusion criteria to participate in this study. The patients were between 14 and 27 years old (five women and two men). The following inclusion criterion was used: patients undergoing upper and lower fixed appliance therapy with 0.022 in. preadjusted edgewise appliances and which required the insertion of $\mathrm{Ti}-\mathrm{Nb}$ archwires (ORMCO Company, CA, USA) with size 0.017 in. $\times 0.025$ in. At the archwire changing appointment, this was carried out as per normal clinical practice.

The wire samples consisted of one randomly selected packet of 0.017 in. $\times 0.025$ in. Ti-Nb wires. Each packet contained ten archwires from a single batch. For each patient included in the test, the excess wire at the distal end was retained, cataloged and placed into a plastic bag at room temperature for storage until testing. Seven distal end cuts from the preformed 0.017 in. $\times 0.025$ in. Ti-Nb archwires (ORMCO Company, CA, USA) were collected this way.

The inserted archwires were retrieved, catalogued and placed into plastic bags at room temperature, following clinical exposure of the remainder of the wire 
(minimum 32 days, maximum 61 days, and average 46 days), prior to testing. The clinically exposed archwires were decontaminated using the following regimen:

1) immersed in a $2 \%$ solution of sodium dodecyl sulphate (SDS) in an ultrasonic water bath for $5 \mathrm{~min}$,

2) wiped for 1 min with cotton pad, soaked in SDS,

3) rinsed with distilled water for $20 \mathrm{~s}$,

4) immersed in a $70 \%$ solution of ethanol for $2 \mathrm{~min}$,

5) air dried.

\subsection{Methods}

\subsubsection{X-ray diffraction(XRD)}

All the samples for the XRD analysis were cut from the same areas/sections of the archwires. The crystalline structure was studied by a Bruker D2 Phaser powder diffractometer with a $\mathrm{Cu}-\mathrm{K}-\alpha$ radiation at $30 \mathrm{kV}$ and $20 \mathrm{~mA}$, with a Scintillation counter Detector, within the range from $5-80^{\circ} 2 \theta$ at a constant step $0.02^{\circ} 2 \theta$.

\subsubsection{Scanning electron microscopy/ Energy dispersive X-ray spectroscopy}

The Scanning electron microscopy (SEM) allows for detailed observation and study of the structure (topography) on the surface of the orthodontic archwires. A scanning electron microscope Zeiss model EVO MA-15 with $\mathrm{LaB}_{6}$ cathode with accelerating voltage range from 0.2 to $30 \mathrm{kV}$ was used for the tests. The investigation was conducted at $20 \mathrm{kV}$. The composition of the samples was determined using energy dispersive X-ray spectroscopy (EDS) method with Bruker Esprit 1.8 system. The accelerating voltage for the EDS measurements was $20 \mathrm{kV}$.

\subsubsection{X-ray photoelectron spectroscopy}

The X-ray photoelectron spectroscopy (XPS) was used for surface analysis. This method can be used for determination of the elemental identity, chemical state, and quantity of a detected element. The measurements were carried out on AXIS Supra electron spectrometer (Kratos Analitycal Ltd.) using a chromatic $\mathrm{Al} \mathrm{Ka}$ radiation with photon energy of $1486.6 \mathrm{eV}$. The energy calibration was performed by normalizing the $\mathrm{C} 1 \mathrm{~s}$ line of adsorbed adventitious hydrocarbons to $284.6 \mathrm{eV}$. The binding energies (BE) were determined with an accuracy of $\pm 0.1 \mathrm{eV}$. The samples were cleaned with $500 \mathrm{eV} \mathrm{Ar}^{+}$ion for $30 \mathrm{~s}$.

\subsubsection{Nanoindentation}

The method uses a high-resolution actuator to control the penetration into the sample surface by the indenter and a high-resolution sensor to continuously measure the penetration depth. The basic benefit of nanoindentation is that the contact area under load can be calculated from the load-displacement data alone, which means that the residual impression does not have to be viewed and measured using complicated imaging techniques, which makes it far easier to measure properties at the sub-micron scale with higher accuracy. Indentation hardness $\left(H_{I T}\right)$ and indentation modulus $\left(E_{I T}\right)$ are the properties determined by means of nanoindentation experiments.

The indentation modulus $E_{I T}$ can be estimated, using the following [8], [22]:

$$
E_{r}=\frac{\sqrt{\pi}}{2 \beta} \frac{S}{\sqrt{A_{c}}},
$$

where $A_{c}$ is the true projected contact area, $S$ is the initial unloading slope, $E_{r}$ is the reduced elastic modulus and $\beta$ is a constant that depends on the geometry of the indenter tip. For the Berkovich indenter tip: $\beta=1.034$. The true projected area is determined using the true contact depth $h_{c}$ and employing the approximation given below with coefficients, obtained after calibration, using indentation data from standard fused silica sample:

$$
A_{c} \approx C_{0} h_{c}^{2}+C_{1} h_{c}+C_{2} h_{c}^{1 / 2}+C_{3} h_{c}^{1 / 4}+C_{4} h_{c}^{1 / 8}+C_{5} h_{c}^{1 / 16} .
$$

The indentation hardness is defined through the ratio of the applied load $P$ and the corresponding true projected contact area:

$$
H_{I T}=\frac{P}{A_{c}} .
$$

The indentation (elastic) modulus $E_{I T}$ of the test material is calculated from Oliver and Pharr [24], using the relation:

$$
E_{I T}=\left(1-v^{2}\right)\left[\frac{1}{E_{r}}-\frac{1-v_{i}^{2}}{E_{i}}\right]^{-1},
$$

where $v$ is the Poisson's ratio for the test material, and $E_{i}$ and $v_{i}$ are the indenter elastic modulus and Poisson's ratio, respectively. In our case, we used the elastic constants for diamond $E_{i}=1141 \mathrm{GPa}$ and $v_{i}=0.07$.

The nanoindentation experiments in the present work were performed in accordance with ISO 14577 standard [16], using Nanoindenter G200 (KLA Corporation, former Agilent Technologies, USA) equipped with 
a Berkovich three-sided diamond pyramid with centerline-to-face angle of $65.3^{\circ}$ and a $20 \mathrm{~nm}$ radius at the tip of the indenter. We used the same indentation method (with load control) at maximum load $=300 \mathrm{mN}, 10 \mathrm{~s}$ peak hold time and one loading-unloading cycle for all tested samples. Each sample was subjected to 12 indentation tests. All measurements were made at room temperature. As a result of the nanoindentation experiments, load-displacement curves were obtained and two mechanical characteristics of the investigated orthodontic wires - indentation hardness $\left(H_{I T}\right)$ and indentation modulus $\left(E_{I T}\right)$ were calculated using Oliver and Pharr approximation method [23].

\subsubsection{Statistical analysis}

The data about the indentation hardness and indentation modulus of the Ti-Nb archwires were presented as mean values and standard deviations ( $( \pm \mathrm{SD})$. We performed one-way analysis of variance (one-way ANOVA) to track changes in these parameters after usage, including three time points: as received, four weeks and six weeks after use in the patient's mouth. The ANOVA analysis was followed by Tukey's post hoc multiple comparisons. The Statistical Package for the Social Sciences (SPSS), Version 26 (2018) was used to perform the statistical tests. The results were interpreted as statistically significant at $p<0.05$.

\section{Results}

\subsection{XRD results}

Figure 1 illustrates a representative X-ray diffraction image taken at room temperature, of as received and clinically retrieved $\mathrm{Ti}-\mathrm{Nb}$ orthodontic archwires. The enlargement, shown on the right, indicates $\mathrm{Ti}-\mathrm{Nb}$ alloy with $\beta$ phase lattice in austenite phase. The XRD scans of all Ti-Nb archwires show eight peaks [110, $200,211,220,310,222,321$ and 400$]$ at $2 \theta$ diffraction angles between $0^{\circ}$ and $50^{\circ}$ (Fig. 1). The crystal system is cubic with parameters $a=b=c=3.2982[\AA]$.

\subsection{EDS and SEM results}

The EDS spectra lines for $\mathrm{Ti}$ and $\mathrm{Nb}$ for the as received, used for 4 weeks and 6 weeks archwires correspond to the literature table values for X-ray emission lines [26] of those elements. Respectively $\mathrm{K}_{\alpha 1}=$ $4.51 \mathrm{keV}, \mathrm{K}_{\beta 1}=4.93 \mathrm{keV}$ and $\mathrm{L}$ emission lines in between $0.40-0.60 \mathrm{keV}$ for $\mathrm{Ti}$ and $\mathrm{L}_{\alpha 1}=2.165 \mathrm{keV}$, $\mathrm{L}_{\beta 1}=2.257 \mathrm{keV}, \mathrm{L}_{\beta 2}=2.367 \mathrm{keV}$ and $\mathrm{L}_{\gamma 1}=2.461 \mathrm{keV}$ for $\mathrm{Nb}$. For the archwires used for 6 weeks there are also spectra lines for $\mathrm{C}$ and $\mathrm{O}$, respectively, at $\mathrm{K}_{\alpha 1}=$ $0.277 \mathrm{keV}$ and $\mathrm{K}_{\alpha 1}=0.524 \mathrm{keV}$.

Table 1 shows that the elemental composition (expressed in wt \%) of $\mathrm{Ti}$ (as received) is $57.47 \mathrm{wt}$. \%, (for 4 weeks) is $57.62 \mathrm{wt} \%$ and (for 6 weeks) 53.06 wt. \%, and $\mathrm{Nb}$ (as received) is $42.52 \mathrm{wt}$ \%, (for 4 weeks) is 42.38 wt. \% and (for 6 weeks) is 46.94 wt. \% in the investigated $\mathrm{Ti}-\mathrm{Nb}$ archwires. The different duration of usage of the wires in the mouth leads to differences in the ratio $\mathrm{Ti} / \mathrm{Nb}$. There is an increase of the concentration of $\mathrm{Ti}$ in the content of the $\mathrm{Ti}-\mathrm{Nb}$ archwires used for 6 weeks, compared to that of the archwires used for 4 weeks (Table 1). In Figures 2, 3 and 4 EDS spectra on one area on both as received and clinically retrieved for 4 and 6 weeks $\mathrm{Ti}-\mathrm{Nb}$ archwires are displayed. Figure 4 shows that beside $\mathrm{Ti}$ and $\mathrm{Nb}$ there is $\mathrm{O}$ and $\mathrm{C}$ on the surface. Visual examination of the SEM micrographs (Fig. 5)


Fig. 1. XRD of as received and clinically retrieved $\mathrm{Ti}-\mathrm{Nb}$ orthodontic archwires 

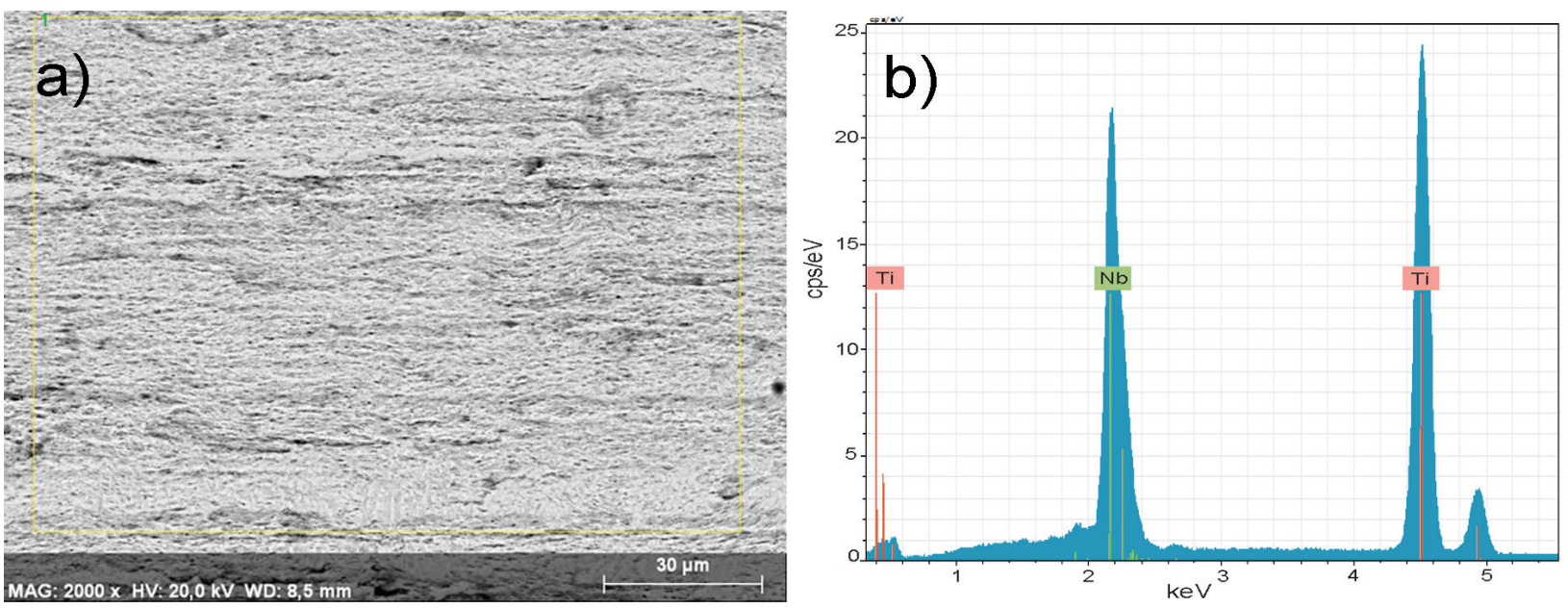

Fig. 2. a) SEM micrograph $(2000 \times)$ and b)EDS spectra of one area of as received $\mathrm{Ti}-\mathrm{Nb}$ archwire
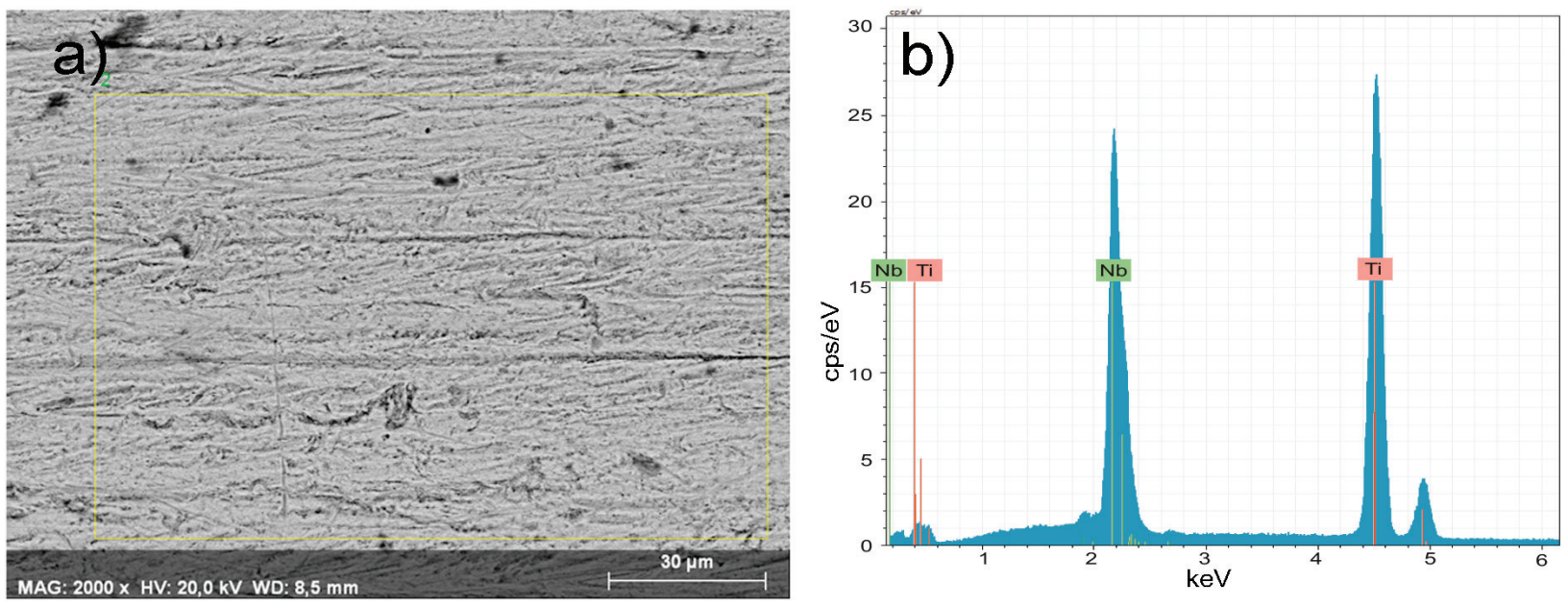

Fig. 3. a) SEM micrograph $(2000 \times)$ and b) EDS spectra of one area of Ti-Nb archwire, clinically retrieved for 4 weeks
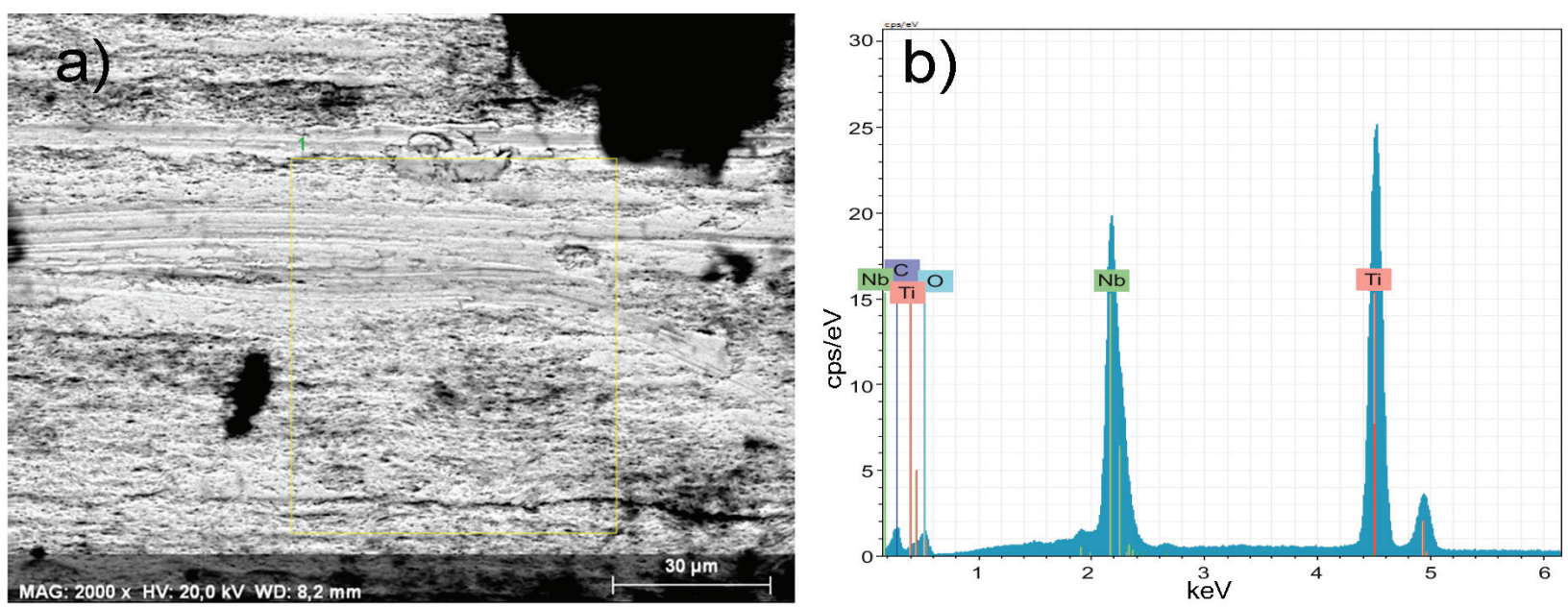

Fig. 4. a) SEM micrograph $(2000 \times)$ and b) EDS spectra of one area of Ti-Nb archwire, clinically retrieved for 6 weeks 

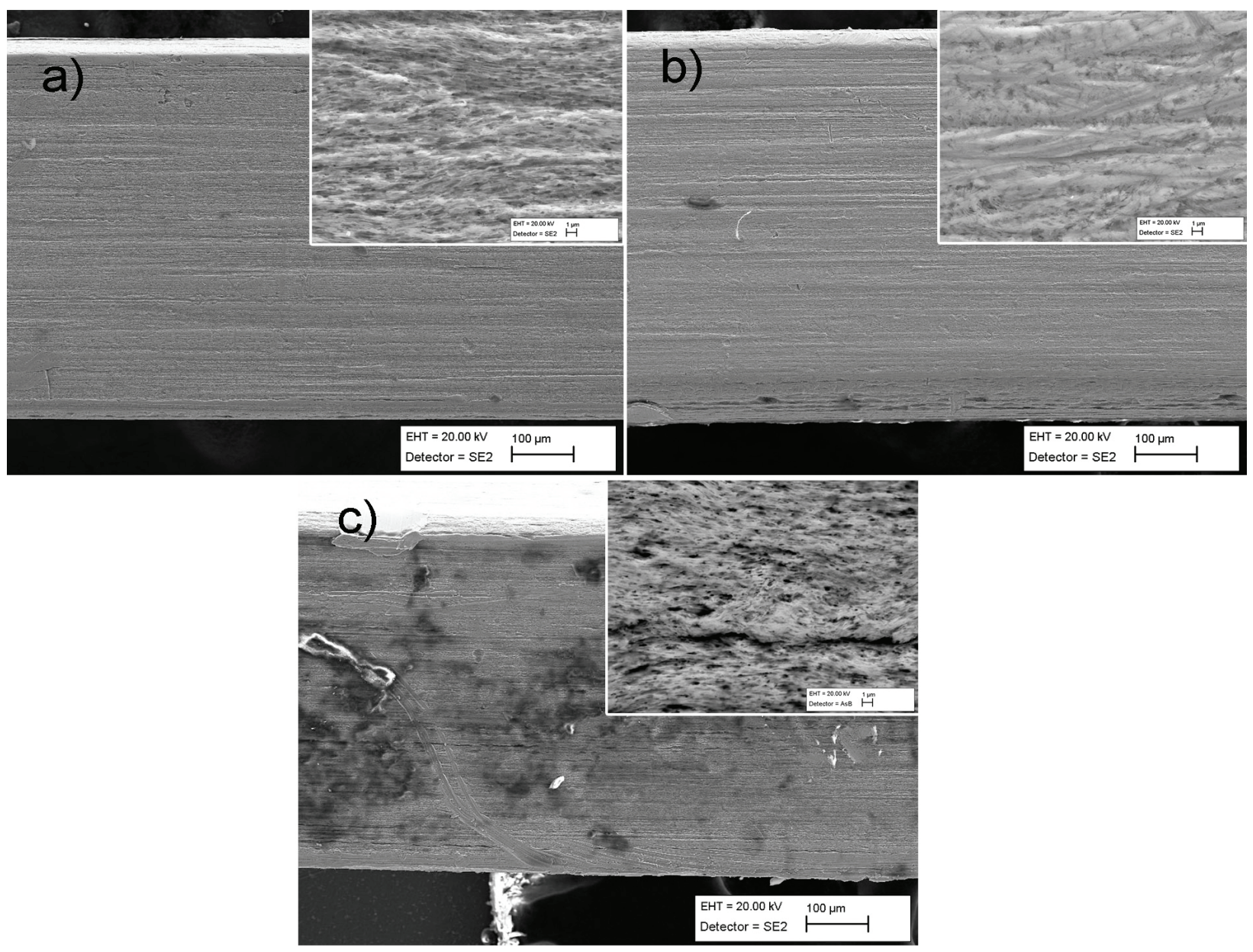

Fig. 5. SEM micrographs of: a) as received, b) clinically retrieved for 4 weeks and c) clinically retrieved for 6 weeks Ti-Nb archwires (the $1 \mu \mathrm{m}$ micrographs are visualized at $\times 10000$ magnification, while the $100 \mu \mathrm{m}$ micrographs are visualized at $\times 300$ magnification)

showed that with prolonged use ( 6 weeks), the morphology of the archwire surface changes. The scratches on the surface become deeper and harder to clean before the sample testing. $\mathrm{C}$ and $\mathrm{O}$ are the main components of all organic compounds and while the archwires are in the oral cavity they are in constant contact with organic materials. We consider that the presence of $\mathrm{C}$ and $\mathrm{O}$ is due to the food and saliva that have remained in those scratches.

\subsection{XPS results}

The XPS spectra of the surface of the clinically retrieved Ti-Nb samples are shown in Fig. 6. The results show that: $\mathrm{Si}, \mathrm{P}, \mathrm{C}$, and $\mathrm{O}$ are mainly present on the surface of each sample. $\mathrm{Na}$ and $\mathrm{Ca}$ are detected and monitored due to surface contamination of the test specimens and therefore the surface of the samples was purged with $\mathrm{Ar}^{+}$ions with energy of $500 \mathrm{eV}$ for $30 \mathrm{~s}$.

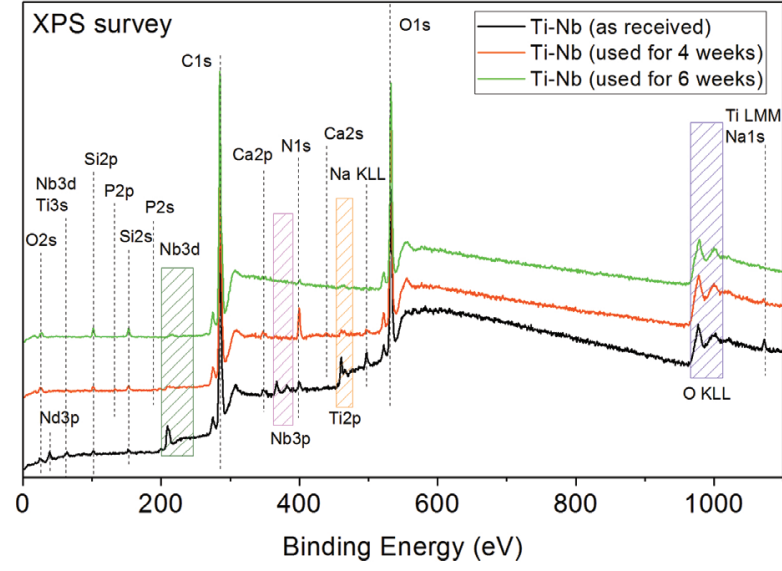

Fig. 6. XPS of as received and clinically retrieved (for 4 weeks and 6 weeks) Ti-Nb archwires

\subsection{Nanoindentation results}

The nanoindenation measurements of the investigated 3 groups of samples (as received, used for 
4 weeks, used for 6 weeks) were made using the same nanoindnentation method with the same input parameters (Section 2.2.4), in order to be able to compare the obtained results. The comparison between indentation hardness and indentation modulus of as received and used for 4 or 6 weeks Ti-Nb archwires is shown in Figs. 7 and 8. The error bars present \% coefficient of variation of measured indentation hardness and indentation modulus, calculated by means of NanoSuite software.

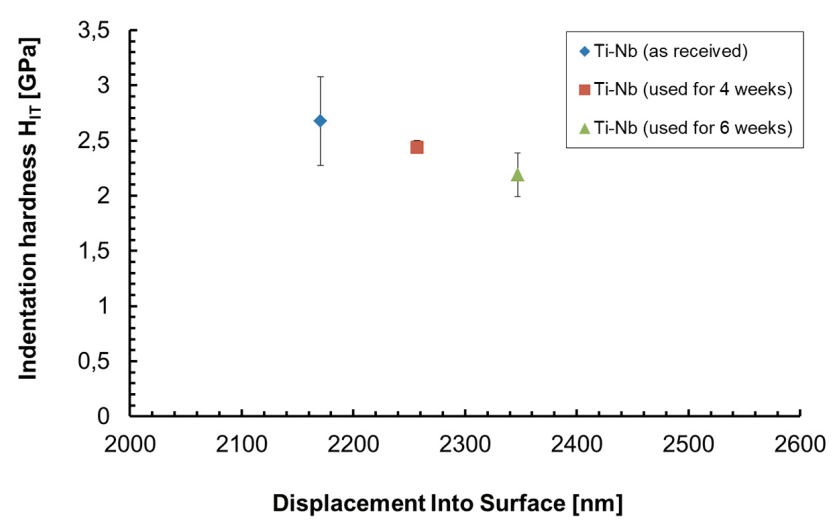

Fig. 7. Comparison between indentation hardness of investigated $\mathrm{Ti}-\mathrm{Nb}$ archwires

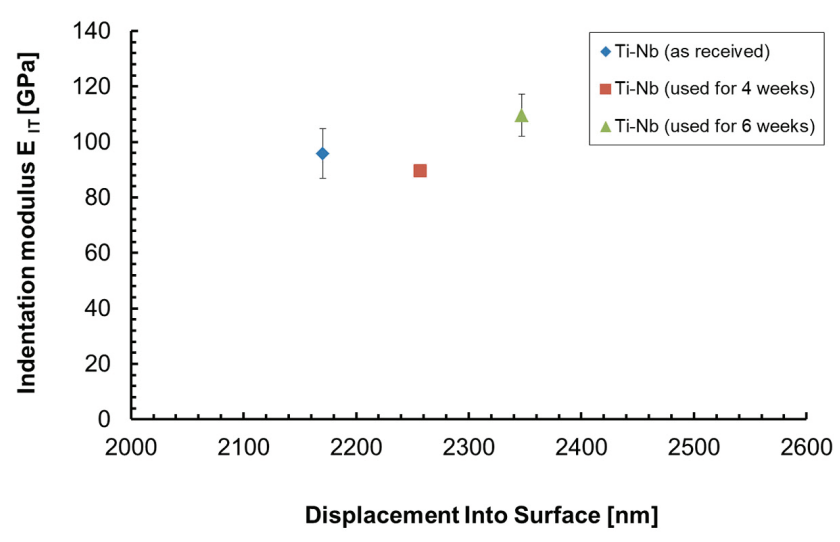

Fig. 8. Comparison between indentation modulus of investigated $\mathrm{Ti}-\mathrm{Nb}$ archwires

The ANOVA analysis revealed a significant decrease in the mean values of indentation hardness over time, $p=0.025$. Through Tukey's post hoc analysis, we determined one significant decrease, between as received $(2.73 \pm 0.43 \mathrm{GPa})$ and six weeks used $(2.19$ $\pm 0.19 \mathrm{GPa}) \mathrm{Ti}-\mathrm{Nb}$ archwires, $p=0.020$. No significant decrease was found between as received and four weeks used Ti-Nb archwires $(2.37 \pm 0.18), p=0.145$; nor between four weeks and six weeks used Ti-Nb archwires, $p=0.560$.

An opposite trend was revealed regarding the change in indentation modulus over time. The ANOVA results showed a significant overall increase in the mean value of this parameter, $p<0.001$. Tukey's post hoc test identified two significant trends: 1) a significant increase in the mean value of indentation modulus between as received $(96.05 \pm 8.1 \mathrm{GPa})$ and six weeks used (109.6 $\pm 7.6 \mathrm{GPa})$ Ti-Nb archwires, $p=0.010$; and 2) a significant increase in the mean value from four weeks used $(89.4 \pm 2.03 \mathrm{GPa})$ to six weeks used Ti-Nb archwires, $p<0.001$. The change between as received and four weeks used $\mathrm{Ti}-\mathrm{Nb}$ archwires was not significant, $p=0.298$.

\section{Discussions}

Because of the high incidence of allergic response to $\mathrm{Ni}$, there is a tendency to avoid Ni-containing materials. One of the possible $\mathrm{Ni}$-free alternatives for the finishing stages of the therapy is the Ti-Nb archwire, whose mechanical properties are not well studied, especially after clinical usage. The inadequacy of such information in the existing literature was the main rationale for the present study, which set out to investigate the mechanical properties, morphology, chemical composition and structure of clinically retrieved $\mathrm{Ti}-\mathrm{Nb}$ orthodontic archwires in order to evaluate the changes of their properties after clinical usage and understand if it is possible to be recycled in the future.

In Figure 7, the gradual decrease of the indentation hardness of the $\mathrm{Ti}-\mathrm{Nb}$ archwires with the increase of their clinical use is illustrated, which we found to be statistically significant between the as received and six weeks used archwires. The observed decrease of the indentation hardness of the $\mathrm{Ti}-\mathrm{Nb}$ orthodontic archwires with the increase in their clinical use is due to the decrease of the concentration of $\mathrm{Ti}$ in the content of the Ti-Nb alloy (Table 1). Additionally, our results revealed an opposite trend regarding the values of the indentation modulus, which increased significantly between the as received and six weeks used $\mathrm{Ti}-\mathrm{Nb}$ orthodontic archwires and between the four weeks and six weeks used $\mathrm{Ti}-\mathrm{Nb}$ orthodontic archwires.

Table 1. Elemental composition of as received and clinically retrieved $\mathrm{Ti}-\mathrm{Nb}$ archwire

\begin{tabular}{|c|c|c|c|c|}
\hline $\begin{array}{c}\mathrm{Ti}-\mathrm{Nb} \text { archwire } \\
0.017 \text { in. } \times 0.025 \text { in. }\end{array}$ & $\begin{array}{c}\text { As received, } \\
\text { wt. \% [13] }\end{array}$ & $\begin{array}{c}\text { Used for } \\
4 \text { weeks, } \\
\text { wt. \% }\end{array}$ & $\begin{array}{c}\text { Used for } \\
6 \text { weeks, } \\
\text { wt. \% }\end{array}$ & $\begin{array}{c}\text { Error } \\
{[\%]}\end{array}$ \\
\hline $\mathrm{Ti}$ & 57.47 & 57.62 & 53.06 & $+/-0.8$ \\
\hline $\mathrm{Nb}$ & 42.52 & 42.38 & 46.94 & $+/-0.8$ \\
\hline
\end{tabular}


Our results about the mechanical properties of as received $\mathrm{Ti}-\mathrm{Nb}$ archwires collaborate with those of other authors [6], [28]; however we can not compare our nanoindentation findings due to a lack of other investigations about used $\mathrm{Ti}-\mathrm{Nb}$ archwires in the literature.

The SEM investigations identified morphological differences among the clinically retrieved $\mathrm{Ti}-\mathrm{Nb}$ archwires. These morphological differences are more pronounced at clinically retrieved after 6 weeks $\mathrm{Ti}-\mathrm{Nb}$ archwire and could be attributed to the different oral hygiene, decomposition of food, leading to acidic saliva and plaque accumulation between the bracket and archwire in the patient's mouth.

The body-centered cubic (BCC) austenite phase can be seen in the XRD results (Fig. 1), while martensitic peaks are absent. The absence of a martensitic phase in $\mathrm{Ti}-\mathrm{Nb}$ wires would indicate better elastic properties. Amorphization was observed which can be due to saliva and contamination during treatment, same as NiTi archwires [13]. The EDS analysis of as received $\mathrm{Ti}-\mathrm{Nb}$ archwires in our previous investigations [12], [13], [25] showed that no additional elements as chromium, cobalt or copper were found, which were registered in other popular archwires like $\mathrm{Ni}-\mathrm{Ti}$ and copper-nickel-titanium. For as received $\mathrm{Ti}-\mathrm{Nb}$ archwire the weight percentages of $\mathrm{Ti}$ and $\mathrm{Nb}$ were 57.47 wt. $\%$ and 42.52 wt. \%, respectively [12]. Bai et al. [4] have reported the weight percentages of Ti and $\mathrm{Nb}$ determined by EDS to be $45.87 \%$ and $54.13 \%$, respectively. Our EDS analysis found that both as received and clinically retrieved $\mathrm{TiNb}$ archwires are composed of the same elements, but in slightly different percentages by weight: $\mathrm{Ti}-57.62 \mathrm{wt} \%$, $\mathrm{Nb}-42.38$ wt. \% (for 4 weeks) and $\mathrm{Ti}-53.06$ wt. \%, $\mathrm{Nb} 46.94$ wt. \% (for 6 weeks).

\section{Conclusions}

In the present work we investigated the chemical composition, the structure, the morphology and mechanical properties of as received and used in clinical practice $\mathrm{Ti}-\mathrm{Nb}$ orthodontic archwires. The results from our nanoindentation investigation showed that there are significant changes in the mechanical properties of the investigated archwires after clinical use. We identified a significant decrease in the indentation hardness of the $\mathrm{Ti}-\mathrm{Nb}$ archwires after clinical use of six weeks, and a significant increase in the indentation modulus after six weeks of use in the patient's mouth. We attribute these changes to the decrease in the concentration of $\mathrm{Ti}$ in the content of the $\mathrm{Ti}-\mathrm{Nb}$ alloy.
Moreover, the SEM investigations identified morphological differences among the clinically retrieved $\mathrm{Ti}-\mathrm{Nb}$ archwires. These changes in mechanical and physicochemical properties of the used $\mathrm{Ti}-\mathrm{Nb}$ archwires could be due to different oral hygiene, decomposition of food, leading to acidic saliva and plaque accumulation between the bracket and archwire in the patient's mouth. For this reason, although there are methods and protocols for recycling of used orthodontic archwires described in the literature [2], [5], [15], [20], we do not consider that it is appropriate to recycle $\mathrm{TiNb}$ archwires.

We plan to continue this line of research as we carry out more in-depth testing of the fracture resistance, which will show if Ti-Nb is applicable to segmental arch techniques, Pendulum springs and others.

\section{Acknowledgements}

This work was supported by the Operational Program of EU "Science and Education for Smart growth" [grant numbers BG05M2OP001-1.001-0003-C01, BG05M2OP001-1.001-0008]; the Bulgarian National Science Fund [grant number H27/29] and a bilateral project between the Bulgarian Academy of Sciences and Estonian Academy of Science, Tallinn University of Technology [grant numbers TAR16016, IUT-T4].

\section{References}

[1] Alcock J.P., Barbour M.E., Sandy J.R., Ireland A.J., Nanoindentation of orthodontic archwires: The effect of decontamination and clinical use on hardness, elastic modulus and surface roughness, Dent. Mater., 2009, 25, 1039-1043.

[2] AL-KHATIEEB M., Influence of different recycling protocols on load deflection of nickel titanium orthodontic wire (An in vitro study), J. Bagh. Coll. Dentistry, 2008, 20, 105-110.

[3] Bai Y.J., Wang Y.B., Cheng Y., Deng F., Zheng Y.F., Wei S.C., Comparative study on the corrosion behavior of $\mathrm{Ti}-\mathrm{Nb}$ and TMA alloys for dental application in various artificial solutions, Mater. Sci. Eng. C, 2011, 31, 702-711.

[4] Bai Y., Deng Y., Zheng Y., Li Y., Zhang R., Lv Y., Zhao Q., WEI S., Characterization, corrosion behavior, cellular response and in vivo bone tissue compatibility of titanium-niobium alloy with low Young's modulus, Mater. Sci. Eng. C, 2016, 59, 565-576.

[5] Bavikati V.N., Singaraju G.S., Mandava P., Killamsetty S.S., NetTAM V., KaRnati P.K., Evaluation of Mechanical and Physical Properties of Clinically Used and Recycled Superelastic NiTi Wires, J. Clin. Diagn. Res., 2016, 10, ZC35-ZC40.

[6] Dalstra M., Denes G., Melsen B., Titanium-niobium, a new finishing wire alloy, Clin. Orthod. Res., 2000, 3, 6-14.

[7] Grimsottir M.R., GJerdet N.R, Hensten-Pettersen A., Composition and in vitro corrosion of orthodontic appliances, Am. J. Orthod. Dentofacial Orthop., 1992, 101, 525-532.

[8] HAY J.L., PHARR G.M., Instrumented Indentation Testing, ASM International, 2000. 
[9] Huang H., Wang C., Chiu S., Wang J., Liaw Y., Lee T., CHEN F., Corrosion behavior of titanium-containing orthodontic archwires in artificial saliva: effects of fluoride ions and plasma immersion ion implantation treatment, J. Dent. Sci., 2005, 24, 134-140.

[10] Iijima M., Muguruma T., Brantley W.A., Mizoguchi I., Comparisons of nanoindentation, 3-point bending, and tension tests for orthodontic wires, Am. J. Orthod. Dentofacial Orthop., 2011, 140, 65-71.

[11] Iijima M., Muguruma T., Brantley W.A., Choe H., NAKAGaKi S., AlaPati S.B., MizOGUCHI I., Effect of coating on properties of esthetic orthodontic nickel-titanium wires, Angle Orthod., 2012, 82, 319-325.

[12] Ilievska I., Karashanova D., Petrunov V., Zaleski A., Drozd M., Mikli V., Stoyanova-Ivanova A.K., Characterization of titanium-niobium orthodontic archwires used in orthodontic treatment, Bulg, Chem, Commun., 2016, 48 Special Issue G, 183-187.

[13] Ilievska I., Petrov V., Andreeva L., Kovacheva D., ZALeski A., Drozd M., Bukowska E., Mikli V., Stoyanova-Ivanova A., Structural and morphological characterization of heat-activated nickel-titanium archwires, Bulg. Chem. Commun., 2017, 49 Special Issue A, 33-39.

[14] Insabralde N.M., Poletti T., Conti A.C., Oltramari-Navarro P.V., Lopes M.B., Flores-Mir C., Rodrigues De Almeida M., Comparison of mechanical properties of beta-titanium wires between leveled and unleveled brackets: an in vitro study, Prog. Orthod., 2014, 15, 42.

[15] Isak J., Mahedira S., Chandrashekar B., Reddy V.P., RAMESH KUMAR P.C., SHETTY B.M., Effects of clinical recycling on mechanical properties of three commonly used types of orthodontic archwires, Saudi J. Oral. Dent. Res., 2016, 1, 124-136.

[16] ISO14577-1, Metallic materials - instrumented indentation test for hardness and materials parameters, International Organization for Standardization, Geneva 2015.

[17] Janson G.R., Dainesi E.A., Consolaro A., Woodside D.G., DE FreITAS M.R., Nickel hypersensitivity reaction before, during, and after orthodontic therapy, Am. J. Orthod. Dentofacial Orthop., 1998, 113, 655-660.
[18] Johnson E., Relative Stiffness of Beta Titanium Archwires, Angle Orthod., 2003, 73, 259-269.

[19] Krishnan V., Kumar K.J., Mechanical Properties and Surface Characteristics of Three Archwire Alloys, Angle Orthod., 2004, 74, 825-831.

[20] Kulshrestha R., Recycling of Nickel Titanium Alloy Wires in Orthodontics, Dentistry and Dent. Pract. J., 2019, 2, 180008.

[21] Nagai M., TANimoto Y., InAmi T.,YAmaguchi M., NISHIYAMA N., KASAI K., Effects of Indentation Load on the Mechanical Behavior of Orthodontic Wire Alloys by Dynamic Micro-Indentation Method, Int. J. Oral-Med. Sci., 2013, 12, 41-48.

[22] Oliver W., Pharr G., Measurement of hardness and elastic modulus by instrumented indentation: Advances in understanding and refinements to methodology, J. Mater. Res., 2004, 19, 3-20.

[23] Oliver W., Pharr G., An improved technique for determining hardness and elastic modulus using load and displacement sensing indentation experiments, J. Mater. Res., 1992, 7, 1564-1583.

[24] Ormco products, archwires. http://www.damonsystem.md/ ortodontical-arcs-en/, [Accessed on 26.09.2019].

[25] Petrov V.G., Terzieva S.D., Tumbalev V.G., Mikli V., ANDREEVA L.S., StOYANOVA-IVANOVA A.K., Influence of the treatment period on the morphology and the chemical composition of the thermally activated orthodontic archwires, Bulg. Chem. Commun., 2015, 47, 234-238.

[26] Thompson A., Attwood D., Gullikson E., Howells M., Kim K., KirZ J., Kortright J., Lindau I., LiU Y., PianetTA P., Robinson A., Scofield J., Underwood J., Williams G., WinICK H., X-ray Data Booklet, Center for X-Ray Optics and Advanced Light Source, Lawrence Berkeley National Laboratory, Berkeley, California 94720, October 2009.

[27] Verstrynge A., Van Humbeeck J., Willems G., In-vitro evaluation of the material characteristics of stainless steel and beta-titanium orthodontic wires, Am. J. Orthod. Dentofacial Orthop., 2006, 130, 460-470.

[28] Zhang D.C., Mao I.F., Li Y.L., Li J.J., Yuan M., Lin J.G., Effect of ternary alloying elements on microstructure and superelastictity of Ti-Nb alloys, Mater. Sci. Eng., A. 2013, $559,706-710$. 